Review

\title{
Improved Performance of Li-ion Polymer Batteries Through Improved Pulse Charging Algorithm
}

\author{
Judy M. Amanor-Boadu ${ }^{1}$ and Anthony Guiseppi-Elie ${ }^{2,3,4,5, * \mathbb{C}}$ \\ 1 Department of Electrical and Computer Engineering, Arizona State University, 650 E. Tyler Mall, Tempe, \\ AZ 85287, USA; jamanorb@asu.edu \\ 2 Center for Bioelectronics, Biosensors and Biochips (C3B), Department of Biomedical Engineering, \\ Texas A\&M University, College Station, TX 77843, USA \\ 3 Department of Electrical and Computer Engineering, Texas A\&M University, College Station, TX 77843, USA \\ 4 Department of Cardiovascular Sciences, Houston Methodist Institute for Academic Medicine and Houston \\ Methodist Research Institute, 6670 Bertner Ave., Houston, TX 77030, USA \\ 5 ABTECH Scientific, Inc., Biotechnology Research Park, 800 East Leigh Street, Richmond, VA 23219, USA \\ * Correspondence: guiseppi@TAMU.edu or guiseppi@tamu.edu; Tel.: +1-979-458-1239; Fax: +1-979-458-8219
}

Received: 10 January 2020; Accepted: 26 January 2020; Published: 29 January 2020

\begin{abstract}
Pulse charging of lithium-ion polymer batteries (LiPo), when properly implemented, offers increased battery charge and energy efficiencies and improved safety for electronic device consumers. Investigations of the combined impact of pulse charge duty cycle and frequency of the pulse charge current on the performance of lithium-ion polymer (LiPo) batteries used the Taguchi orthogonal arrays $(\mathrm{OA})$ to identify optimal and robust pulse charging parameters that maximize battery charge and energy efficiencies while decreasing charge time. These were confirmed by direct comparison with the commonly applied benchmark constant current-constant voltage (CC-CV) charging method. The operation of a pulse charger using identified optimal parameters resulted in charge time reduction by $49 \%$ and increased charge and energy efficiencies of $2 \%$ and $12 \%$ respectively. Furthermore, when pulse charge current factors, such as frequency and duty cycle were considered, it was found that the duty cycle of the pulse charge current had the most impact on the cycle life of the LiPo battery and that the cycle life could be increased by as much as 100 cycles. Finally, the charging temperature was found to have the most statistically significant impact on the temporarily evolving LiPo battery impedance, a measure of its degradation.
\end{abstract}

Keywords: battery charging; Li-ion polymer battery; pulse charging; constant current constant voltage; battery impedance; cycle life; Taguchi orthogonal array; design of experiments

\section{Introduction}

In the age of ubiquitous use of lithium-ion polymer ( $\mathrm{LiPo}$ ) batteries in many battery-powered portable electronic devices [1], battery charging has become an imperative topic of research. Inappropriate and ineffective battery charging can have adverse effects on the battery and hence result in limited battery cycle life or even thermal runaway. Electronic device consumers are increasingly desiring prolonged battery usage and faster battery charge times. This desire has driven researchers to investigate energy storage devices with increased energy density, lower discharge rate, and sustained safer fast charging [2,3]. Researchers are also exploring different charging algorithms that increase battery charge and energy efficiencies, decrease charge time, and ensure longer battery cycle life [4-6]. The energy storage device of choice for most consumer electronics are lithium-ion (Li-ion) batteries [1]. Market research project li-ion batteries to reach USD 67.7 billion by 2022 and USD 92 billion by 2024 [7,8]. This is due to their high energy density and low self-discharge rate. However, drawbacks include 
stringent charging requirements and high cost. LiPo batteries use gel-like polymer electrolytes that aids in a more flexible form factor and lighter weight [9]. The difference between LiPo batteries and Li-ion batteries is the electrolyte. In the regular Li-ion batteries, liquid electrolytes based on lithium salts in organic solvents are used. However, Li-ion polymer batteries use a high-conductivity polymeric semisolid to support the electrolyte and improve ion movement compared to Li-ion batteries, which use a liquid electrolyte [9]. The polymeric semisolid allows the battery to be formed in different form factors with the additional advantages of improved safety and good mechanical strength. LiPo batteries are therefore used in many portable electronic devices because of these favorable characteristics.

These batteries have stringent charging algorithms and such algorithms can go a long way to increase battery cycle life, decrease charging time, and help improve charge and energy efficiencies [10]. One of the most popular and acknowledged gold standard charging algorithms for LiPo batteries is the constant current-constant voltage $(\mathrm{CC}-\mathrm{CV})$ charging algorithm. This algorithm is also considered the benchmark against which all other proposed charging methods are compared.

\subsection{CC-CV Charging Algorithm}

The CC-CV charging algorithm has three charging phases: (i) Trickle charging phase, (ii) constant current charging phase, and (iii) constant voltage charging phase. The trickle charging phase is initiated when the battery is significantly discharged and a small charge current, usually $1 \%$ to $10 \%$ of the full rated charge current, is used for charging. The constant current charge phase can have a charge current ranging from $50 \%$ to $320 \%$ of the full rated charge current to charge the battery [11]. During this charging phase, the voltage of the battery quickly rises, and measures must be taken to prevent overvoltage conditions. In the constant voltage charging phase, a decreasing charge current is used in this phase to prevent overcharge and overvoltage conditions, which can be detrimental to the LiPo battery. Charging time is prolonged in this phase due to the use of decreasing charge current. Figure 1 schematically illustrates the temporal CC-CV charging algorithm.

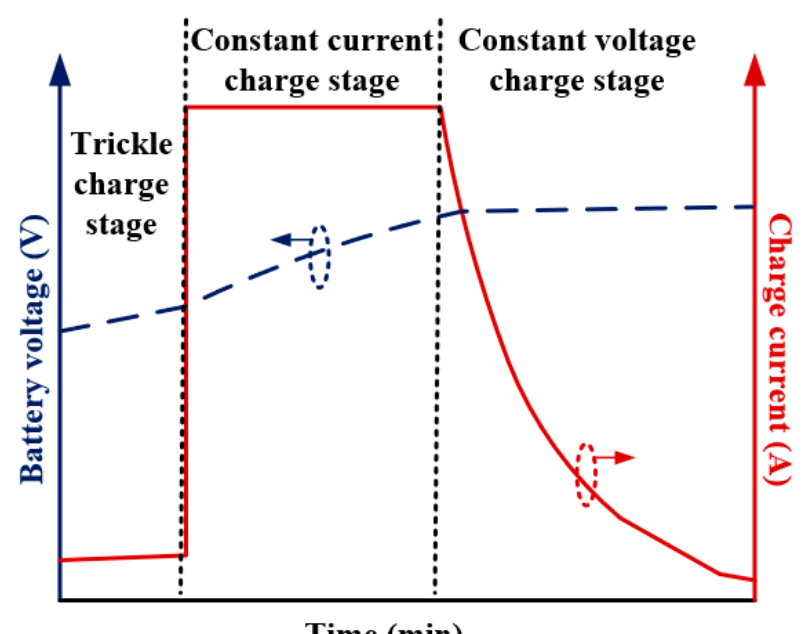

Time (min)

Figure 1. Schematic illustration of the constant current-constant voltage (CC-CV) charging algorithm.

The main drawbacks of the CC-CV charging algorithm are its longer charge time and decreased battery energy and charge efficiencies, which results in shorter battery runtimes. Increased battery runtime and shorter charging times, two important performance metrics electronic device consumers desire, can be addressed by the charging algorithm. Electrochemical-based modelling, where charging control algorithms are based on the movement of lithium ions, was developed [12-14] to address some of the shortcomings of the CC-CV charging algorithm. Other works [15-18] have proposed the use of orthogonal arrays to search for the best charging patterns to increase charge efficiency and cycle life. The use of fuzzy logic and probabilistic techniques to adapt the battery charging based on the 
current state of charge (SoC) were also developed [6,19-23]. Several authors $[19,24,25]$ have proposed charging techniques based on the polarization of the battery, taking into account the temporarily evolving internal impedance of the battery. Other battery charging algorithms [18,26-33] use pulse and sinusoidal waveforms to charge the battery. Of these proposed charging algorithms, the most promising and simple is the pulse charging algorithm.

\subsection{Pulse Charging Algorithm}

Pulse charging algorithms, when properly designed and implemented, can result in significant benefits in terms of improved battery charge and energy efficiencies, longer battery cycle life, and decreased battery charge time. Pulse charging involves the use of charge current pulses, which have carefully controlled duty cycle, frequency, and peak amplitude to charge the LiPo battery. Figure 2 shows a pictorial representation of the waveforms of a pulse charger under operation. These carefully controlled charge current pulses ensure that the lithium ions that are electrochemically produced during each pulse from the cathode migrates to the anode and successfully intercalate before the next group of ions arrive at that electrode. This prevents accumulation of $\mathrm{Li}^{+}$ions on the surface of the electrode and hence mitigates dendrite formation, which is detrimental to the battery cycle life and inherently can be a safety risk [34]. In the CC-CV charging algorithm, the decreasing current used in the CV stage is needed to prevent the undesirable effects of dendrite formation, such as the rupturing of the battery separator, which can lead to thermal runaway.

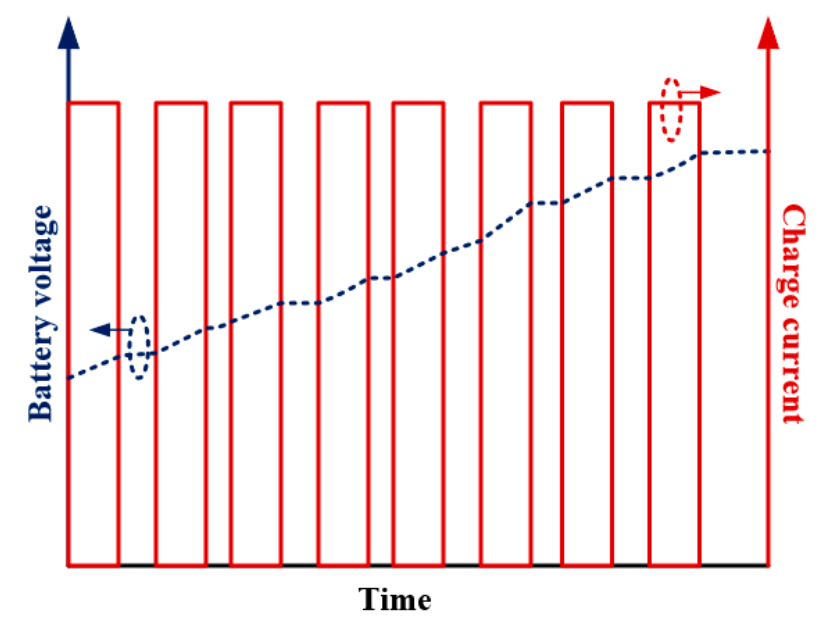

Figure 2. Waveforms of a pulse charger under operation.

Numerous researches have been conducted in the area of pulse charging. Chen [27] proposed a pulse charging strategy whereby the duty cycle was constantly changing to ensure the battery was charged efficiently. Yin et al. [32] developed a technique to dynamically change the frequency of the applied pulses used for charging to minimize battery impedance and improve charge time. Chen [26] also proposed a variable frequency approach for the pulse charger to enhance battery performance. The key to the successful implementation of the pulse charging algorithm is the careful selection of the pulse charger parameters, which include peak charge current amplitude, frequency, and duty cycle. This paper therefore summarizes the combined impact of these parameters, in addition to the ambient temperature at which the battery is charged, on charge time, battery charge, and energy efficiencies, and battery cycle life. This paper is divided into five sections. Section 2 will summarize the key findings on the impact of frequency, duty cycle, peak amplitude, and ambient temperature at which selected LiPo batteries were charged on battery charge time, and battery charge and energy efficiencies. Section 3 will review key findings on the impact of these pulse charging parameters, discussed in Section 2, on battery cycle life and battery impedance characteristics. Section 4 discusses various 
opportunities in the area of battery charging and where the future of battery charging algorithms is headed. Conclusions are then drawn in Section 5.

\section{Determination of Optimal Pulse Charging Parameters}

This section reviews the use of an optimization process to determine the optimal pulse charging parameters.

\subsection{Pulse Charging Parameters}

Every pulse charger has the following parameters that need to be controlled in order to reap the benefits of pulse charging. These parameters are related as shown in Equation (1), where $f$ is frequency, $I_{\text {peak }}$ is the peak charge current amplitude, $T_{o n}$ is the time the battery is being charged, $I_{a v g}$ is the average charge current, and $D$ is the duty cycle of the pulses.

$$
I_{\text {avg }}=I_{\text {peak }} \cdot f \cdot T_{\text {on }}
$$

Figure 3 shows the role of these parameters in a simplified schematic of a pulse charger.

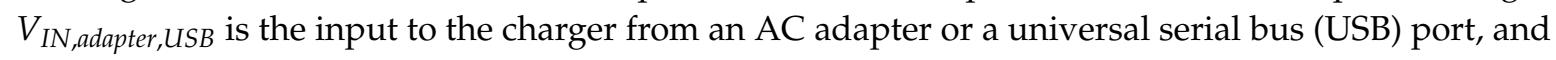
the transistor, Switch, switches on and off, pulsating the charge current into the battery depending on the frequency and duty cycle of the control block. $I_{\text {peak }}$ can be controlled depending on the user application and specifications of the batteries.

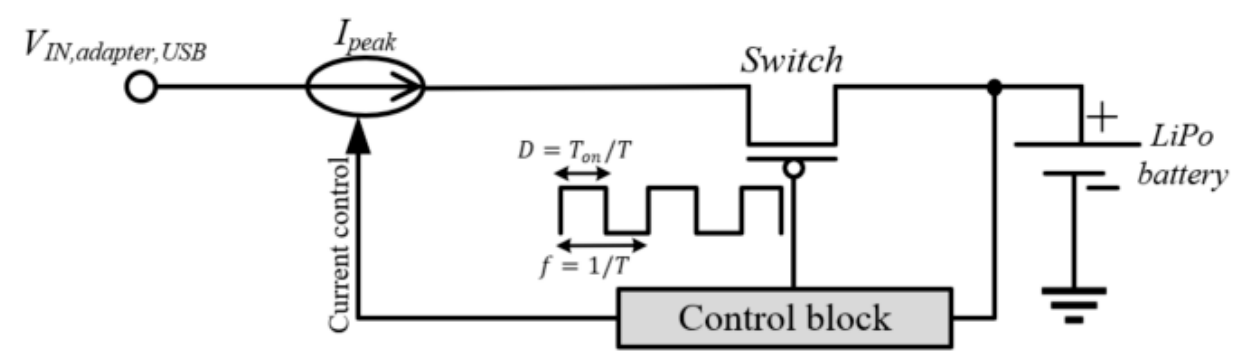

Figure 3. General overview of a pulse charger.

The battery charge and energy efficiencies are estimated as follows

$$
\begin{gathered}
E f f_{C E}=100 * \frac{\int_{0}^{t_{d i s}} I_{d i s} \cdot d t}{\int_{0}^{t_{c h}} I_{c h} \cdot d t} \\
E f f_{E E}=100 * \frac{\int_{0}^{t_{d i s}} V_{d i s} I_{d i s} \cdot d t}{\int_{0}^{t_{c h}} V_{c h} I_{c h} \cdot d t}
\end{gathered}
$$

respectively, where $E f f_{C E}$ is the battery charge efficiency, $E f f_{E E}$ is the battery energy efficiency, $t_{d i s}$ is the discharge time, $t_{c h}$ is the charge time, $I_{d i s}$ is the discharge current, $I_{c h}$ is the charge time, and $V_{d i s}$ and $V_{c h}$ are the average discharge and charge voltages.

In previous works $[26,27,31,32]$, the different combination of these parameters, i.e., $I_{\text {peak }}, D$, and $f$, resulted in different performances of the pulse charger. It was therefore necessary to determine which of these parameters and their respective values resulted in the best battery performance. The investigation of which combinations resulted in the best performance required a large number of one-variable-at-a time experiments, therefore making the process time consuming and costly. Orthogonal arrays can be used to solve the problem of large experimental domain size. Orthogonal arrays (OA) represent a design of experiment (DoE) technique that seeks to give comparable results to full factorial designs. Taguchi OA, which was developed by Genichi Taguchi [35], is a robust experimental design method. It reduces 
the number of experiments but ensures the results are comparable to fully factorial designs. Taguchi OA design process consists of tolerance design, parameter design, and system design. Tolerance design takes into account the random parameters that can influence the design of a system, an example can be the random manufacturing variations across different batteries under test, while parameter design is identifying the various factors that impact the design of the system. The parameters that can be controlled, in this case, can be duty cycle or frequency of the charge current. System design considers the design of a circuit, model, or process, by understanding what is expected. In this context, the battery charger is the system.

\subsection{Impact of Pulse Charging Parameters}

The pulse charging parameters investigated to determine their impact on battery performance were frequency, duty cycle, and the ambient temperature at which the battery was charged. The Li-ion polymer battery used in these experiments had a chemical composition of a lithium cobalt oxide cathode, graphite anode, lithium hexafluorophosphate electrolyte, and a microporous film blend of polyethylene and polypropylene for the separator. A limited number of experiments was used to determine which parameters and parameter values resulted in an improved performance of a Li-ion polymer battery and which combination ensured a faster charging and increased battery charge and energy efficiencies. Each OA has both input and output parameters. The input parameters were selected to be duty cycle, frequency, and ambient temperature at which the battery was charged. The duty cycle and temperature were set at three levels each with the duty cycle at $20 \%, 50 \%$, and $80 \%$ and ambient temperature at $0{ }^{\circ} \mathrm{C}, 23{ }^{\circ} \mathrm{C}$, and $45^{\circ} \mathrm{C}$, respectively. The frequency at which the pulse charger was operated was set at six levels, i.e., $0.1 \mathrm{kHz}, 1 \mathrm{kHz}, 6 \mathrm{kHz}, 12 \mathrm{kHz}, 50 \mathrm{kHz}$, and $100 \mathrm{kHz}$. These parameters are summarized in Figure 4. In this work [18], an important frequency point was included in the selected levels, i.e., $12 \mathrm{kHz}$ the frequency at which the minimum impedance of the battery under test occurred. The impact of this frequency on the performance metrics of the LiPo was investigated. The outputs of the OA were established to be charging time, battery charge, and energy efficiencies. Based on the number of inputs and the selected levels, the OA row size was determined to be 36 [36] and experiments were conducted according to the OA combinations and results recorded.

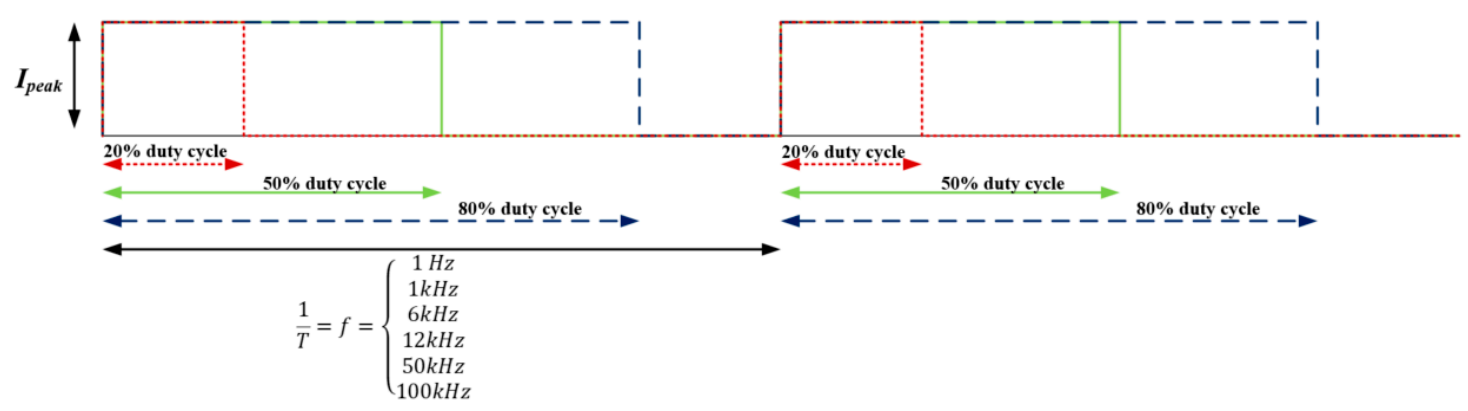

Figure 4. Pulse charging input parameters for the Taguchi orthogonal arrays (OA) design of experiment (DoE).

The results were analyzed using a number of statistical methods such as analysis of means and analysis of variance. Each factor and their level were examined and their impact on the performance metrics of the battery determined. When investigating the impact of ambient temperature, it was noticed that at $45^{\circ} \mathrm{C}$, there was a shorter charge time compared to charging at $0{ }^{\circ} \mathrm{C}$. Poor battery charge and energy efficiencies were also observed at $0^{\circ} \mathrm{C}$. This can be attributed to the limited mobility of $\mathrm{Li}$ ions at $0{ }^{\circ} \mathrm{C}$. Comparable efficiencies were observed at $23^{\circ} \mathrm{C}$ and $45^{\circ} \mathrm{C}$. However, sustained charging at $45^{\circ} \mathrm{C}$ could lead to accelerated degradation of the cycle life of the battery. Charging at $50 \%$ duty cycle produced the largest battery charge and energy efficiencies, with $20 \%$ duty cycle having about $25 \%$ less efficiency and $80 \%$ duty cycle having an average of $5 \%$ less. Investigating the different frequencies under test, frequencies outside the $12 \mathrm{kHz}$ range, i.e., $0.1 \mathrm{kHz}, 1 \mathrm{kHz}, 6 \mathrm{kHz}, 50 \mathrm{kHz}$, 
and $100 \mathrm{kHz}$, produced poor battery charge and energy efficiencies, while frequencies less than $6 \mathrm{kHz}$ and greater than $50 \mathrm{kHz}$ produced longer charge times. Energy losses were minimized in the range of frequencies where the battery impedance was minimum, specifically at $12 \mathrm{kHz}$, thereby resulting in improved performance.

The input parameters that had the most impact on the performance metrics of the LiPo battery and at which particular levels they occurred were investigated. Frequency and duty cycle were determined to have the largest impact on the performance of the battery and specifically, at $12 \mathrm{kHz}$, i.e., the frequency at which the battery impedance was minimum, and 50\% duty cycle, which gives enough time for the $\mathrm{Li}^{+}$ions to intercalate in the electrodes. A confirmation experiment was run using these parameters at room temperature and compared with the benchmark constant current-constant voltage charging algorithm. It was concluded that operating a pulse charger at the optimal levels for the selected input parameters, the pulse charger could have an $12 \%$ improvement in battery energy efficiency and $2 \%$ improvement of battery charge efficiency over CC-CV method. There was also a $48 \%$ reduction in charge time. Figures 5 and 6 summarize these comparisons.

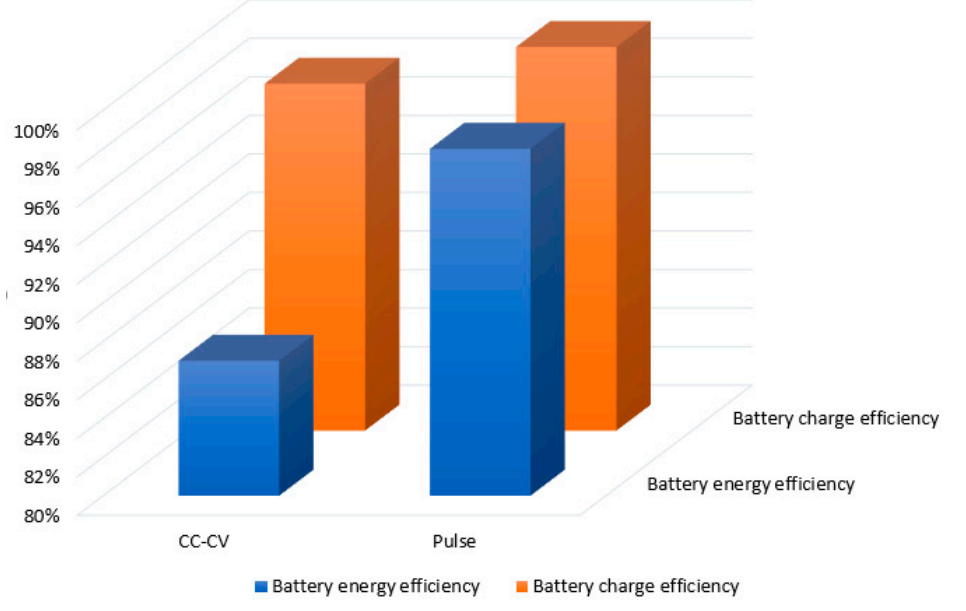

Figure 5. Comparison of battery charge and energy efficiencies between $\mathrm{CC}-\mathrm{CV}$ and pulse charged batteries.

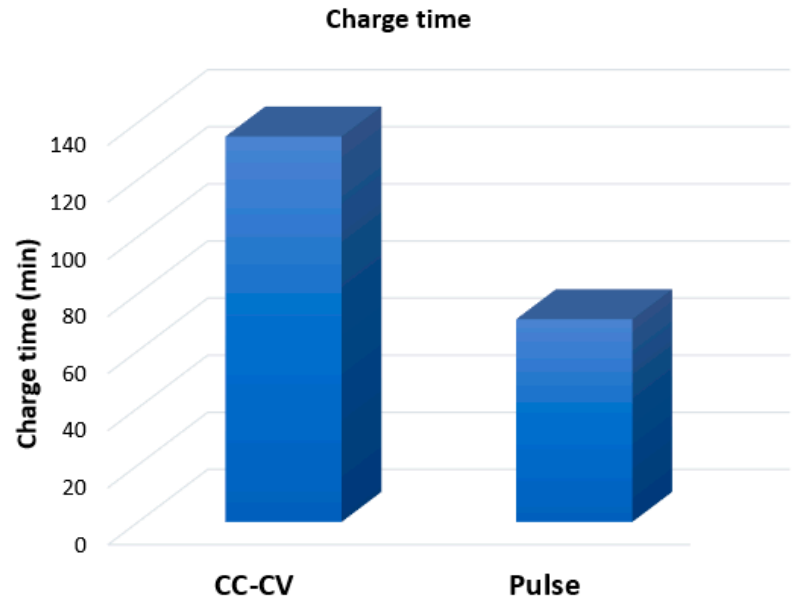

Figure 6. Comparison of charge time between $\mathrm{CC}-\mathrm{CV}$ and pulse charged batteries.

The impact of the peak amplitude of the pulse charging current was investigated [18] and it was observed that the higher the peak current, the faster the charging time of the LiPo battery. Though the battery charged faster, safety circuits had to be activated to terminate charging in order to prevent overcharge and overvoltage conditions. The early termination of charging resulted in the LiPo battery being under capacity, which resulted in reduced runtime. Another drawback to increasing the 
peak amplitude of the charge current was the increase in surface temperature of the battery during charging, which quickly approached unsafe charging temperatures. These conditions could prove to be detrimental to the cycle life and safety of the battery. The peak charge current amplitude should therefore be within the specifications of the battery.

\section{The Impact of Pulse Charging Parameters on Cycle Life of Lipo Batteries}

The impact of using a pulse charging algorithm, specifically the pulse charger parameters, on the cycle life of a LiPo battery was investigated [37]. Similar to Section 2, the parameters investigated were duty cycle, frequency, and the ambient temperature at which the battery was charged. The parameter levels were similarly set as: Duty cycle of $20 \%, 50 \%$, and $80 \%$, ambient temperature of $0{ }^{\circ} \mathrm{C}, 23{ }^{\circ} \mathrm{C}$, and $45^{\circ} \mathrm{C}$, and frequency at which the pulse charger was operated at $0.1 \mathrm{kHz}, 1 \mathrm{kHz}, 6 \mathrm{kHz}, 12 \mathrm{kHz}$, $50 \mathrm{kHz}$, and $100 \mathrm{kHz}$. Using these parameters, a 36-row sized orthogonal array was constructed and experiments conducted in accordance with this DoE. It was observed that the inherent battery impedance increased as the charge and discharge cycles increased for both pulse charged and CC-CV charged batteries. As the battery is subjected to an increasing number of charge and discharge cycles, various side chemical reactions occur, which can affect the battery impedance. Across temperature, LiPo batteries charged at $0{ }^{\circ} \mathrm{C}$ using the standard $\mathrm{CC}-\mathrm{CV}$ algorithm had lower battery impedance compared to those that were pulse charged. A similar trend was also observed at $45^{\circ} \mathrm{C}$. However, at $23^{\circ} \mathrm{C}$, both batteries subjected to pulse charging and CC-CV charging has similar impedance values. When analyzing the factors that impacted battery impedance, a LiPo battery pulse charged at a duty cycle of $50 \%$, had lower impedance compared to that pulsed at duty cycles of $20 \%$ and $80 \%$ after 400 charge and discharge cycles.

When determining which factors affected battery cycle life, it was observed that the cycle life of the battery increased when the battery was pulsed at the frequency at which its impedance was minimum (in this case, $12 \mathrm{kHz}$ ) and at a $50 \%$ duty cycle. These two parameters had the greatest impact on the cycle life of the battery. A 50\% duty cycle meant equal time allocated to anode and cathode reversal while charging at the lowest impedance meant highest conversion of input energy into stored energy. Ambient temperature, $23^{\circ} \mathrm{C}$, also enhanced battery cycle life when compared to charging the battery at $0{ }^{\circ} \mathrm{C}$ and $45^{\circ} \mathrm{C}$. Charging the LiPo battery at frequencies below that which the minimum impedance occurred resulted in a shorter cycle life, while charging at the higher frequencies still resulted in shorter cycle life when compared to the optimal charging frequency. The pulse charging of a LiPo battery at the optimal parameters, i.e., $50 \%$ duty cycle, $12 \mathrm{kHz}$ (frequency at which minimum battery impedance occurred), and $23^{\circ} \mathrm{C}$, resulted in an additional 100 cycles when compared with a battery charged using the standard $\mathrm{CC}-\mathrm{CV}$ charging algorithm. Figure 7 summarizes the remaining capacity of batteries that were subjected to pulse charging using optimal parameters as compared to those using standard $\mathrm{CC}-\mathrm{CV}$ charging. Pulse charging using the right charging parameters could enhance the cycle life of batteries, ensuring that batteries are seldomly replaced, resulting in overall cost reduction and environmental burden. It was also deduced that in some circumstances, e.g., under extreme temperatures, $\mathrm{CC}-\mathrm{CV}$ can be used in order to improve battery impedance and ensure longer cycle life. This leads to the potential for the implementation of a temperature dependent algorithm selection. 


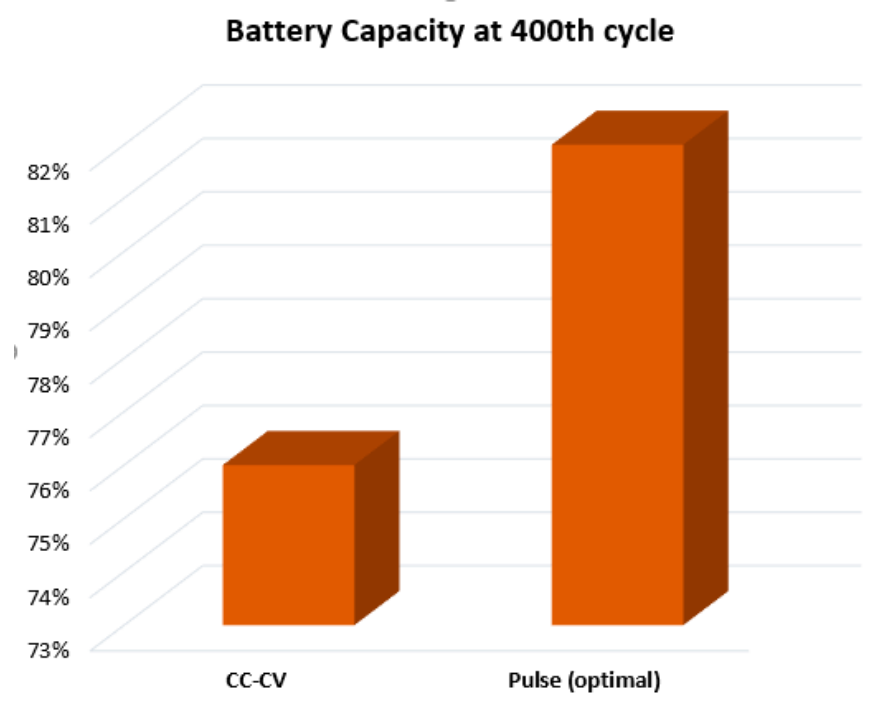

Figure 7. Remaining battery capacity after 400 charge/discharge cycles at room temperature for standardly (CC-CV) charged and optimally pulsed charged LiPo batteries.

A comparison of this work was made with other state-of-the-art pulse charging techniques. This is summarized in Table 1. The impact of the proposed pulse charging algorithms on the cycle life of batteries are not evaluated in most previous works. It is important to evaluate the benefits of proposed pulse charging algorithms across both charge time and cycle life to prevent frequent replacement of batteries, which is something this work evaluates.

Table 1. Comparison between various pulse charging algorithms.

\begin{tabular}{cccccc}
\hline & {$[26]$} & {$[27]$} & {$[32]$} & {$[33]$} & This Work \\
\hline Battery type & Li-ion & Li-ion & Li-ion & Li-ion & LiPo \\
Battery capacity (mAh) & 600 & 500 & 2500 & 1000 & 600 \\
Voltage range (V) & $3.4-4.2$ & $3.3-4.2$ & $3.2-4.2$ & $3.2-4.2$ & $3.1-4.1$ \\
Charge current $(\mathrm{mA})$ & 600 & 230 & $1250-4000 *$ & $611-250 *$ & 300 \\
Charge time $(\mathrm{min})$ & 118 & 190 & 58 & 51 & 71 \\
Cycle life & $\mathrm{n} / \mathrm{a}$ & $\mathrm{n} / \mathrm{a}$ & $\mathrm{n} / \mathrm{a}$ & $\mathrm{n} / \mathrm{a}$ & $>400$ cycles \\
\hline
\end{tabular}

* Alternating peak pulse currents used.

\section{The Future of Battery Charging}

The findings resulting from these studies conducted on finding the optimal pulse charging parameters using a design of experiments approach reinforces the need to ensure that proper battery charging algorithms are developed to guarantee improved battery charge and energy efficiencies, reduced charging times, and longer cycle life across various environmental conditions and applications. It can therefore be required to have a combination of different charging algorithms that can be optimally selected based on factors such as temperature, device operation, state of charge, number of charge and discharge cycles, battery impedance, and consumer needs. For this we coin the phrase "smart charging" to describe a system of sensor-enabled charging algorithm selection to ensure that the performance metrics of the LiPo batteries are always optimized according to the application and environmental circumstance.

The development of innovative rechargeable batteries dictates that corresponding charging algorithms are developed that can ensure longer cycle life, improved runtime, and decreased charge time at a lower cost. Ionic materials [38] have developed a lithium battery that uses a sloid plastic electrolyte to enhance malleability, increase energy density, and improve safety. A lithium or sodium doped glass as battery electrolyte to increase the energy storage capability of the battery was debuted by Braga et al. [39]. A porous silicon battery was developed in [40] by etching silicon wafers and 
coating them with metals to form micro batteries. This new technology prevents dendrite formation and makes the battery easily recyclable. A battery with a silicon rich anode material was presented by Exponential Energy (XNRGI) [41], where this anode material could increase battery capacity and due to its reduced thickness, it could be charged in a shorter time. With these battery innovations and other prospective ones summarized in [42-45], there will be a need to understand the fundamentals of the ion movements in these batteries and the redox and intercalation chemistry behind their performance to ensure that proper charging algorithms are developed accordingly.

As new battery technologies continue to emerge and are still not ubiquitously used or mass manufactured yet, li-ion based batteries will continue to be used in a number of widespread applications. Consumers of these battery powered applications are always looking for the capability of fast charging their batteries. Hence, charging algorithms still need to be continually developed whereby li-ion batteries can relatively be charged in a few minutes without compromising the safety of the device or the user while achieving longer runtimes. With regards to pulse charging, optimized performance can be obtained when charging at frequencies, which corresponds to that at which the minimum battery impedance occurs. Future pulse charging algorithms should therefore consider novel ways to perform in-situ battery impedance measurements and with alteration of charging parameters based on the current battery impedance in a seamless manner, since battery impedance versus frequency changes over time.

The use of artificial intelligence in battery charging will also become prevalent. With the use of machine learning algorithms being applied in many of today's applications, it is only instinctive that the art of battery charging heads towards that direction too, with energy efficiency, reduced complexity, safety, and charging speed as the focused objectives.

\section{Conclusions}

Pulse charging has been known to confer a shorter charge time, and higher battery charge and energy efficiencies when compared to the benchmark CC-CV charging algorithm. However, there has not been much work to delve into which of the pulse charging parameters affect the performance metrics of the LiPo battery. This paper presented a summarization of the impact of the pulse charging parameters, i.e., duty cycle and frequency, on the charging time, cycle life, and the charge and energy efficiencies of the battery. This work has demonstrated that selecting the right pulse charging parameters can prolong the cycle life of the LiPo battery, reduce charge time, and improved the battery charge and energy efficiencies, thereby increasing battery runtime. The impact of the various levels of these parameters were also investigated and a duty cycle of $50 \%$ proved decisive in increasing cycle life and ensuring shorter charge time. The ambient temperature at which the battery was charged was also investigated. Finally, the concept of "smart charging" was introduced as a way to align internal and external parameters with the applicable charging algorithm and which moves us towards the development and application of $\mathrm{AI}$ in battery charging.

Author Contributions: Conceptualization, J.M.A.-B. and A.G.-E.; methodology, J.M.A.-B.; software, J.M.A.-B.; validation, J.M.A.-B.; formal analysis, J.M.A.-B.; investigation, J.M.A.-B.; resources, A.G.-E.; writing-original draft preparation, J.M.A.-B. and A.G.-E.; writing-review and editing, J.M.A.-B., A.G.-E.; supervision, A.G.-E. All authors have read and agreed to the published version of the manuscript.

Funding: This research received no external funding.

Acknowledgments: The authors want to acknowledge Edgar Sanchez-Sinencio of the Analog and Mixed Signal group at Texas A\&M University for support in performing this research.

Conflicts of Interest: The authors declare no conflict of interest.

\section{References}

1. Zubi, G.; Dufo-López, R.; Carvalho, M.; Pasaoglu, G. The lithium-ion battery: State of the art and future perspectives. Renew. Sustain. Energy Rev. 2018, 89, 292-308. [CrossRef]

2. Kai, B.P. Modern Battery Engineering: A Comprehensive Introduction; World Scientific: Singapore, 2019. 
3. Li, M.; Lu, J.; Chen, Z.; Amine, K. 30 Years of Lithium-Ion Batteries. Adv. Mater. 2018, 30, 1800561. [CrossRef]

4. Hussein, A.A.-H.; Batarseh, I. A Review of Charging Algorithms for Nickel and Lithium Battery Chargers. IEEE Trans. Veh. Technol. 2011, 60, 830-838. [CrossRef]

5. Yilmaz, M.; Krein, P.T. Review of Battery Charger Topologies, Charging Power Levels, and Infrastructure for Plug-In Electric and Hybrid Vehicles. IEEE Trans. Power Electron. 2013, 28, 2151-2169. [CrossRef]

6. Asadi, H.; Kaboli, S.; Oladazimi, M.; Safari, M. A review on Li-ion battery charger techniques and optimize battery charger performance by fuzzy logic. Int. Conf. Inf. Intell. Comput. 2011, 18, 89-96.

7. Market Research Engine, Lithium Ion Battery Market Global Forecast by 2018-2024, Nov., 2018. Available online: https://www.marketresearchengine.com/lithium-ion-battery-market1 (accessed on 3 September 2019).

8. Zion Market Research, Outlook: Lithium-Ion Battery Market to Flourish and Will Reach to USD 67.70 Billion by 2022. Available online: https:/www.globenewswire.com/news-release/2019/07/27/1892570/0/en/ReportOutlook-Lithium-Ion-Battery-Market-To-Flourish-and-Will-Reach-to-USD-67-70-Billion-by-2022.html (accessed on 3 September 2019).

9. Song, J.; Wang, Y.; Wan, C. Review of gel-type polymer electrolytes for lithium-ion batteries. J. Power Sources 1999, 77, 183-197. [CrossRef]

10. Zhang, S.S. The effect of the charging protocol on the cycle life of a Li-ion battery. J. Power Sources 2006, 161, 1385-1391. [CrossRef]

11. Kim, B.G.; Tredeau, F.P.; Salameh, Z.M. Fast chargeability lithium polymer batteries. In Proceedings of the 2008 IEEE Power and Energy Society General Meeting-Conversion and Delivery of Electrical Energy in the 21st Century, Pittsburg, PA, USA, 20-24 July 2008; pp. 1-5.

12. Chu, Z.; Feng, X.; Lu, L.; Li, J.; Han, X.; Ouyang, M. Non-destructive fast charging algorithm of lithium-ion batteries based on the control-oriented electrochemical model. Appl. Energy 2017, 204, 1240-1250. [CrossRef]

13. Lin, X.; Hao, X.; Liu, Z.; Jia, W. Health conscious fast charging of Li-ion batteries via a single particle model with aging mechanisms. J. Power Sources 2018, 400, 305-316. [CrossRef]

14. Methekar, R.; Ramadesigan, V.; Braatz, R.D.; Subramanian, V.R. Optimum Charging Profile for Lithium-Ion Batteries to Maximize Energy Storage and Utilization. ECS Trans. 2010, 25, 139-146.

15. Lee, C.-H.; Chang, T.-W.; Hsu, S.-H.; Jiang, J.-A. Taguchi-based PSO for searching an optimal four-stage charge pattern of Li-ion batteries. J. Energy Storage 2019, 21, 301-309. [CrossRef]

16. Wang, S.C.; Huang, J.W.; Liu, Y.H.; Hsieh, C.H. The implementation of consecutive orthogonal array method on searching optimal five step charging pattern for Lithium-ion batteries. In Proceedings of the 9th World Congress on Intelligent Control and Automation, Taipei, Taiwan, 21-25 June 2011; pp. 358-363.

17. Cheng, P.-J.; Cheng, C.-H.; Hong, S.-B. Optimal battery chargers for photovoltaic system based on fuzzy theory and Taguchi method. In Proceedings of the 2013 International Conference on Advanced Robotics and Intelligent Systems, Tainan, Taiwan, 31 May-2 June 2013; pp. 70-75.

18. Amanor-Boadu, J.M.; Guiseppi-Elie, A.; Sanchez-Sinencio, E. Search for Optimal Pulse Charging Parameters for Li-Ion Polymer Batteries Using Taguchi Orthogonal Arrays. IEEE Trans. Ind. Electron. 2018, 65, 8982-8992. [CrossRef]

19. Jiang, J.; Zhang, C.; Wen, J.; Zhang, W.; Sharkh, S.M. An Optimal Charging Method for Li-Ion Batteries Using a Fuzzy-Control Approach Based on Polarization Properties. IEEE Trans. Veh. Technol. 2013, 62, 3000-3009. [CrossRef]

20. Liu, Y.-H.; Teng, J.-H.; Lin, Y.-C. Search for an Optimal Rapid Charging Pattern for Lithium-Ion Batteries Using Ant Colony System Algorithm. IEEE Trans. Ind. Electron. 2005, 52, 1328-1336. [CrossRef]

21. Wang, S.-C.; Chen, Y.-L.; Liu, Y.-H.; Huang, Y.-S. A fast-charging pattern search for li-ion batteries with fuzzy-logic-based Taguchi method. In Proceedings of the 2015 IEEE 10th Conference on Industrial Electronics and Applications (ICIEA), Auckland, New Zealand, 15-17 June 2015; pp. 855-859.

22. Liu, C.-L.; Wang, S.-C.; Liu, Y.-H.; Tsai, M.-C. An optimum fast charging pattern search for Li-ion batteries using particle swarm optimization. In Proceedings of the 6th International Conference on Soft Computing and Intelligent Systems, and the 13th International Symposium on Advanced Intelligence Systems, Kobe, Japan, 20-24 November 2012; pp. 727-732.

23. Ullah, Z.; Burford, B.; Dillip, S. Fast intelligent battery charging: Neural-fuzzy approach. IEEE Aerosp. Electron. Syst. Mag. 1996, 11, 26-34. [CrossRef] 
24. Jiang, J.; Liu, Q.; Zhang, C.; Zhang, W. Evaluation of Acceptable Charging Current of Power Li-Ion Batteries Based on Polarization Characteristics. IEEE Trans. Ind. Electron. 2014, 61, 6844-6851. [CrossRef]

25. Stephens, J.F.; Moss, P.L.; Morris, L., Jr.; Weatherspoon, M.H. Dynamic Pulse Charging Scheme for Series Connected Cells. In Proceedings of the 231st ECS Meeting, New Orleans, LA, USA, 28 May-1 June 2017.

26. Chen, L.-R. A Design of an Optimal Battery Pulse Charge System by Frequency-Varied Technique. IEEE Trans. Ind. Electron. 2007, 54, 398-405. [CrossRef]

27. Chen, L.-R. Design of duty-varied voltage pulse charger for improving li-ion battery-charging response. IEEE TIE 2009, 56, 480-487.

28. Chen, L.-R.; Wu, S.-L.; Chou, C.-P.; Chen, T.-R. Design of sinusoidal current charger with optimal frequency tracker for Li-ion battery. In Proceedings of the 2010 International Power Electronics Conference-ECCE ASIA, Sapporo, Japan, 21-24 June 2010; pp. 1484-1489.

29. Di Yin, M.; Youn, J.; Park, D.; Cho, J. Efficient Frequency and Duty Cycle Control Method for Fast Pulse-Charging of Distributed Battery Packs by Sharing Cell Status. In Proceedings of the 2015 IEEE 12th Intl Conf on Ubiquitous Intelligence and Computing and 2015 IEEE 12th Intl Conf on Autonomic and Trusted Computing and 2015 IEEE 15th Intl Conf on Scalable Computing and Communications and Its Associated Workshops (UIC-ATC-ScalCom), Beijing, China, 10-14 August 2015; pp. 1813-1818.

30. Savoye, F.; Venet, P.; Millet, M.; Groot, J. Impact of Periodic Current Pulses on Li-Ion Battery Performance. IEEE TIE 2012, 59, 3481-3488. [CrossRef]

31. Chen, L.-R.; Chen, J.-J.; Ho, C.-M.; Wu, S.-L.; Shieh, D.-T. Improvement of Li-ion Battery Discharging Performance by Pulse and Sinusoidal Current Strategies. IEEE TIE 2013, 60, 5620-5628. [CrossRef]

32. Yin, M.; Cho, J.; Park, D. Pulse-Based Fast Battery IoT Charger Using Dynamic Frequency and Duty Control Techniques Based on Multi-Sensing of Polarization Curve. Energies 2016, 9, 209. [CrossRef]

33. Purushothaman, B.K.; Landau, U. Rapid Charging of Lithium-Ion Batteries Using Pulsed Currents. J. Electrochem. Soc. 2006, 153, A533. [CrossRef]

34. Ely, D.R.; García, R.E. Heterogeneous Nucleation and Growth of Lithium Electrodeposits on Negative Electrodes. J. Electrochem. Soc. 2013, 160, A662-A668. [CrossRef]

35. Taguchi, G. Experimental Designs; Maruzen Publishing Company: Tokyo, Japan, 1976.

36. Phadke, M.S. Quality Engineering Using Robust, 2nd ed.; Pearson: London, UK, 2009.

37. Amanor-Boadu, J.M.; Guiseppi-Elie, A.; Sánchez-Sinencio, E. The Impact of Pulse Charging Parameters on the Life Cycle of Lithium-Ion Polymer Batteries. Energies 2018, 11, 2162. [CrossRef]

38. Mark Anderson, Ionic Materials Expands Lab Where It Makes Safer, More Efficient Lithium Batteries from Plastic, IEEE Spectrum, 29 May 2018. Available online: https://spectrum.ieee.org/energywise/semiconductors/ materials/welcome-to-the-ionyl-age (accessed on 25 December 2019).

39. Braga, M.H.; Grundish, N.S.; Murchison, A.J.; Goodenough, J.B. Alternative strategy for a safe rechargeable battery. Energy Environ. Sci. 2017, 10, 331-336. [CrossRef]

40. XNRGI. Breakthrough Battery Architecture Solves Key Issues of Energy Storage; XNRGI: Bothell, DC, USA, 2019.

41. Enables Mass Adoption for EV's \& Renewable Energy. 2019. Available online: https://xnrgi.com/media/ (accessed on 25 December 2019).

42. Schneider, D. To Boost Lithium-Ion Battery Capacity by up to 70\%, Add Silicon, 6 January 2019. Available online: https://spectrum.iee.org/energy/renewables/to-boost-lithiumion-battery-capacity-by-up-to-70-addsilicon (accessed on 25 December 2019).

43. Zhu, G.; Zhao, C.; Huang, J.; He, C.; Zhang, J.; Chen, S.; Xu, L.; Yuan, H.; Zhang, Q. Fast Charging Lithium Batteries: Recent Progress and Future Prospects. Small 2019, 15, e1805389. [CrossRef]

44. He, Y.; Matthews, B.; Wang, J.; Song, L.; Wang, X.; Wu, G. Innovation and challenges in materials design for flexible rechargeable batteries: From 1D to 3D. J. Mater. Chem. A 2018, 6, 735-753. [CrossRef]

45. Xia, S.; Wu, X.; Zhang, Z.; Cui, Y.; Liu, W. Practical Challenges and Future Perspectives of All-Solid-State Lithium-Metal Batteries. J. Chem. 2019, 5, 753-785. [CrossRef]

(C) 2020 by the authors. Licensee MDPI, Basel, Switzerland. This article is an open access article distributed under the terms and conditions of the Creative Commons Attribution (CC BY) license (http://creativecommons.org/licenses/by/4.0/). 